\title{
Klinische uitkomsten na implantatie van een speciaal voor de falloplastiek ontwikkelde erectieprothese
}

\author{
Garry L. S. Pigot · Joost W. van Leeuwen · Freek P. W. de Rooij · Brechje L. Ronkes · Wouter B. van der Sluis · \\ Mark-Bram Bouman
}

Geaccepteerd op: 12 januari 2022 / Published online: 21 februari 2022

(C) The Author(s) 2022

Samenvatting Dit artikel beschrijft de klinische uitkomsten na implantatie van de erectieprothese voor de falloplastiek bij transmannen. Bijgehouden zijn hun demografische gegevens, type prothese (hydraulisch of semirigide), operatieve gegevens en intra- en postoperatieve complicaties. Daarnaast werd nagegaan hoeveel procent van de mannen seksueel actief was met penetratieve seks. Van de 18 semirigide erectieprothesen werd er één verwijderd vanwege dreigende erosie en werden er vier gewisseld naar de hydraulische. Van deze 42 werden er vier $(9,5 \%)$ verwijderd vanwege een infectie, bij vier mannen werd een $(9,5 \%)$ langere prothese geplaatst en vonden vijf $(11,9 \%)$ heroperaties plaats vanwege materiaalproblematiek. Implantatie van de voor falloplastiek ontwikkelde erectieprothese laat gunstige resultaten zien. Het merendeel van de mannen is in staat tot penetratieve seks.

Trefwoorden transgender mannen - falloplastiek · hydraulische erectieprothese $\cdot$ semirigide erectieprothese

dr. G. L. S. Pigot $(\bowtie) \cdot$ J. W. van Leeuwen, MSc .

drs. F. P. W. de Rooij · drs. B. L. Ronkes

afdeling Urologie, Amsterdam UMC, Amsterdam, Nederland garry.pigot@amsterdamumc.nl

dr. W. B. van der Sluis · prof. dr. M.-B. Bouman

afdeling Plastische, Reconstructieve en Hand chirurgie,

Amsterdam UMC, Amsterdam, Nederland

dr. G. L. S. Pigot · J. W. van Leeuwen, MSc .

drs. F. P. W. de Rooij · drs. B. L. Ronkes · dr. W. B. van

der Sluis · prof. dr. M.-B. Bouman

Kennis Centrum Gender Dysforie, Amsterdam UMC,

Amsterdam, Nederland

\section{Clinical outcomes after implantation of an erectile prosthesis specially developed for phalloplasty}

Abstract This article describes the clinical outcomes after implantation of the erectile prosthesis for phalloplasty in trans men. Demographic data, type of prosthesis (hydraulic or semi-rigid), operative data and intra- and post-operative complications were collected. In addition, it was examined what percentage of the men were sexually active with penetrative sex. Of the 18 semi-rigid erectile prostheses, one was removed due to impending erosion and four were switched to the hydraulic one. Of these 42 , four $(9.5 \%)$ were removed because of an infection, in four men a (9.5\%) longer prosthesis was placed and five (11.9\%) reoperations were performed due to material problems. Implantation of the erectile prosthesis developed for phalloplasty shows favorable results. The majority of men are capable of penetrative sex.

Keywords transgender men $\cdot$ phalloplasty $\cdot$ hydraulic erection prosthesis $\cdot$ semi-rigid erection prosthesis

\section{Introductie}

Transgender mannen (mannen bij wie het geboortegeslacht niet overeenkomt met het gewenste geslacht) kunnen voor de genitale geslachtsaanpassende operatie (gGAO) kiezen tussen de metaidoioplastiek en de falloplastiek. Bij de metaidoioplastiek wordt lokaal weefsel (hypertrofische clitoris, labia majora en labia minora) gebruikt voor de constructie van het genitaal. Voordelen van de operatie zijn dat de postoperatieve sensibiliteit goed is en dat er weinig littekens worden gemaakt. Een genoemd nadeel is het kleinere formaat van de neofallus. Bij de falloplastiek wordt de neofallus gereconstrueerd uit een vrije of gesteelde lap en 
wordt het scrotum van lokaal weefsel (labia majora, labia minora, clitoris huid en prepubisch vet) gemaakt.

Ontwikkelingen in de loop der jaren hebben voor een verbetering van de technieken van de gGAO gezorgd en ertoe geleid dat er bij de constructie van de falloplastiek meer lappen (onderarm, bovenbeen of flank/lies) kunnen worden gebruikt en/of gecombineerd [1]. Waar in het verleden de ontwikkelingen waren gericht op het ontwikkelen van de ideale fallus voor iedereen, zijn tegenwoordig de idealen van het individu bepalender voor de gGAO [2]. Een van de redenen om te kiezen voor een falloplastiek is de wens om penetratieve seks te beleven [3]. Dit vereist echter rigiditeit van de neofallus, wat in de meeste gevallen bij transmannen implantatie van een erectieprothese noodzakelijk maakt.

In de loop der jaren zijn er al verschillende typen prothesen ontwikkeld voor het verbeteren van de rigiditeit van de natuurlijke fallus van cisgender mannen (mannen bij wie het gewenste geslacht overeenkomt met het aangeboren geslacht) [4]. Speciaal voor mannen met een falloplastiek zijn sinds een paar jaar een hydraulische (fig. 1) en een semirigide erectieprothese (fig. 2) op de markt [5, 6].

Transmannen die in aanmerking komen voor een erectieprothese zijn minimaal één jaar postoperatief na falloplastiek (vanwege het herstel van het gevoel in de neofallus), hebben geen secundaire operaties aan het genitaal meer nodig en hebben seksuologi- sche counseling achter de rug. Tijdens die gesprekken wordt het seksueel functioneren besproken en wordt geëvalueerd wat de verwachtingen zijn van het seksueel functioneren na implantatie van de erectieprothese.

In dit artikel worden uitkomsten gepresenteerd van een studie die is uitgevoerd bij transmannen na implantatie van de erectieprothese die is ontwikkeld voor de falloplastiek.

\section{Methode}

De gegevens van alle transgender mannen die in ons centrum een erectieprothese geïmplanteerd kregen tussen 1 januari 2017 en 1 september 2021 zijn retrospectief geanalyseerd. Hiertoe werd een retrospectief statusonderzoek verricht, waarin werden bijgehouden: de demografische gegevens van de deelnemers, het type prothese (hydraulisch of semirigide) dat werd geïmplanteerd, de operatieve gegevens en intra- en de postoperatieve complicaties, zoals infectie, erosie of andere complicaties. Daarnaast werd geïnventariseerd hoeveel procent van de mannen seksueel actief waren. Statistisch onderzoek bestond uit het berekenen van de gemiddelden met de spreiding.

Er werd informed consent verkregen en het onderzoek werd goedgekeurd door de medisch-ethische toetsingscommissie van het Amsterdam UMC, referentienummer 2018625.

Figuur 1 Zephyr Surgical Implants $(Z S I){ }^{\circledR}$, Genève, Zwitserland. ZSI 475 hydraulische erectieprothese. Lichtfoto (a) en schematische weergave van de plaatsing ervan (b). Bron: www.zsimplants.ch, met toestemming geplaatst
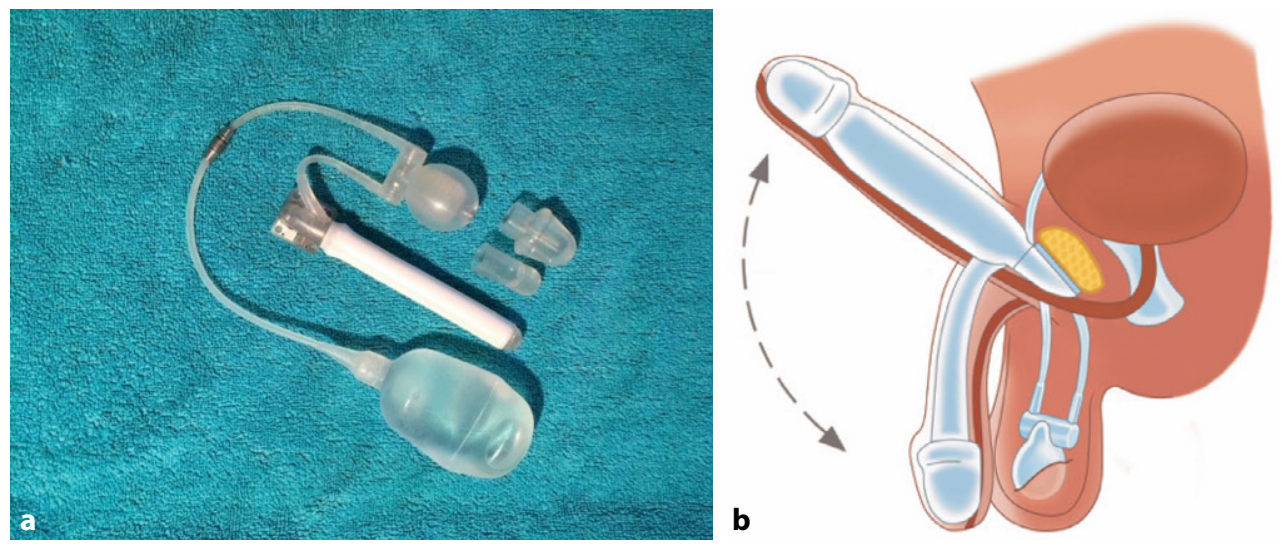

Figuur 2 Zephyr Surgical Implants $(Z \mathrm{SI})^{\circledR}$, Genève, Zwitserland. 100D en ZSI 100 semirigide erectieprothese. Lichtfoto (a) en schematische weergave van de plaatsing ervan (b). Bron: www.zsimplants.ch, met toestemming geplaatst
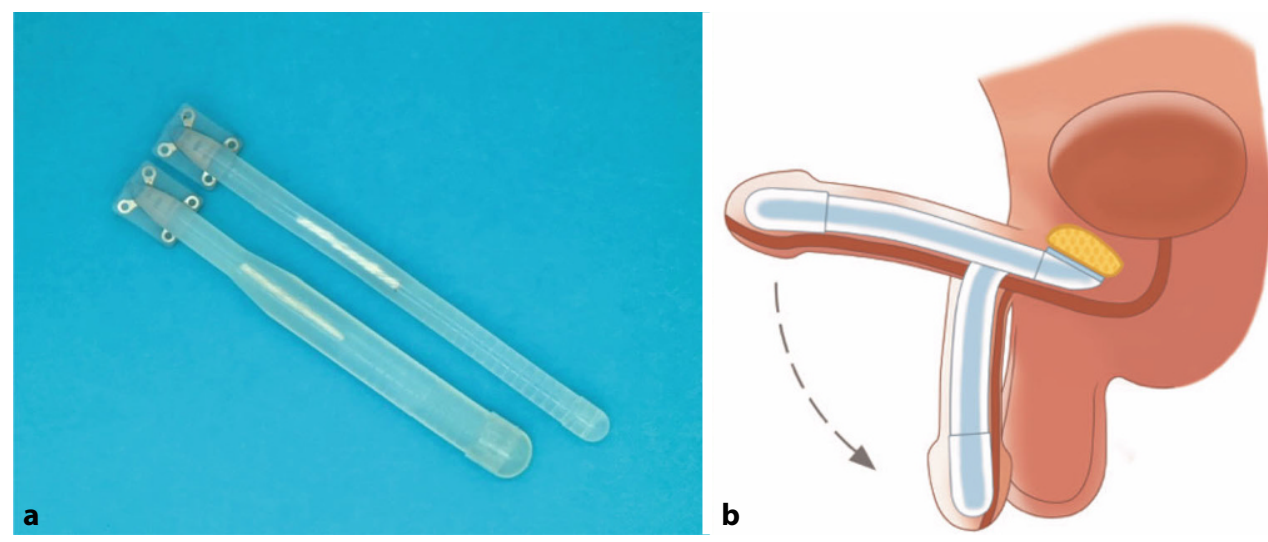
Chirurgische procedure voor de plaatsing van een erectieprothese

Patiënten worden in rugligging onder algehele anesthesie geopereerd met een cefalosporine antibioticum als profylaxe. Het operatiegebied wordt met handzeep gewassen en na afdrogen tweemaal gepoetst met chloorhexidine. Bij voorkeur wordt er een transurethrale katheter geplaatst. Bij mannen met de plasbuisverlenging dient deze ter bescherming van de urethra.

Bij mannen die een hydraulische prothese krijgen, wordt de katheter ingebracht om blaasperforatie te voorkomen ten tijde van het plaatsen van het reservoir. Parascrotaal wordt een verticale incisie gemaakt, bij voorkeur aan de contralaterale kant van de vaatsteel van de neofallus. De caudale zijde van het os pubis wordt vervolgens vrijgelegd tot op het periost, rekening houdend met de positie van de (begraven) clitoris en de neo-urethra. Vervolgens worden er vier niet-oplosbare hechtingen geplaatst in vierkante configuratie. Vervolgens wordt de neofallus gedilateerd met de Hegar-stiften tot ongeveer $1 \mathrm{~cm}$ onder de top van de neofallus. Vervolgens wordt de lengte van de te gebruiken prothese gemeten. Het os pubis wordt lokaal geïnfiltreerd met bupivacaïne.

Een semirigide prothese wordt eerst op maat gesneden en daarna gefixeerd met de eerder geplaatste hechtingen. Indien de lengte goed is, wordt de wond in lagen gesloten met oplosbare hechtingen. Bij het plaatsen van de hydraulische prothese wordt er eerst een holte voor de pomp gemaakt aan de kant van het scrotum waar de incisie is gemaakt. Indien er al testisprothesen zijn geplaatst wordt er één vervangen door de pomp. $\mathrm{Na}$ het maken van de holte voor de pomp wordt via een aparte incisie ter hoogte van het lieskanaal retropubisch ruimte gemaakt voor het plaatsen van het reservoir. $\mathrm{Na}$ het uitpakken van de juiste maat prothese wordt deze luchtledig gemaakt en gedrenkt in een rifampicine/gentamicine-oplossing. Vervolgens wordt het reservoir geplaatst en gevuld met $\mathrm{NaCl}$. Het buisje dat afkomstig is van het reservoir wordt via de lieswond naar de scrotale wond geleid. De prothese wordt met de eerder geplaatste hechtingen gefixeerd en de pomp wordt lateraal in het scrotum geplaatst. Na proefconnectie wordt de prothese opgeblazen. Als deze correct zit, vindt de definitieve connectie plaatst waarbij de buisjes vaak ingekort dienen te worden. De wonden worden gesloten waarbij het met name van belang is dat de prothesedelen bedekt zijn met meerdere lagen weefsel. De hydraulische prothese wordt tot slot half opgeblazen.

\section{Resultaten}

Tussen 1 januari 2017 en 1 september 2021 werd in ons centrum bij 54 transgender mannen een erectieprothese geïmplanteerd. Bij acht van deze mannen betrof het een re-implantatie na een ander merk erectieprothese. Relevante demografische voorgeschiedenis betrof CVA $(n=1)$ en diabetes mellitus type $2(n=1)$. Bij in totaal 42 patiënten was een falloplastiek aangebracht, waarvan 30 met en 12 zonder plasbuisverlenging. De gemiddelde leeftijd ten tijde van implantatie was $37 \pm 11$ jaar.

Er werden 16 primaire semirigide erectieprothesen geplaatst. Hiervan werd er één postoperatief verwijderd vanwege dreigende erosie van het implantaat. Bij vier mannen werd de prothese vervangen door een hydraulische versie, aangezien ze niet tevreden waren over het semirigide karakter ervan. Alle mannen met een semirigide erectieprothese in situ ten tijde van de analyse waren hiermee seksueel actief.

Naast de vier secundaire hydraulische prothesen werden 38 primaire hydraulische prothesen geplaatst. Van alle 42 prothesen moesten er uiteindelijk vier $(9,5 \%)$ verwijderd worden vanwege een infectie. In vier gevallen $(9,5 \%)$ was her-operatie nodig omdat initieel niet de goede maat prothese was gekozen. In vijf gevallen $(11,9 \%)$ vond her-operatie plaats vanwege materiaalproblematiek, zoals lekkage. In één geval werd zowel cilinder als pomp verwijderd vanwege pijnklachten, in één geval werd het reservoir chirurgisch naar intra-abdominaal verplaatst, ook vanwege pijnklachten. De ruime meerderheid van de mannen met een erectieprothese in situ was in staat om een erectie te krijgen. De gemiddelde klinische follow-up was 13 maanden.

\section{Discussie}

Het plaatsen van een erectieprothese na een falloplastiek is een technisch uitdagende ingreep waarbij de kans op complicaties en heroperaties groot is, maar het resultaat verbetert met het toenemen van de ervaring [6]. Op basis van de wens van de transman, zijn fysieke gesteldheid (i.e. handfunctie en mobiliteit), sociale activiteiten (bijvoorbeeld sauna of zwemmen) en de dimensies van de fallus (lengte en dikte), wordt er uiteindelijk een keuze gemaakt voor het type implantaat: semirigide of hydraulisch. De rigiditeit van beide prothesen geeft de mogelijkheid tot penetratieve seks.

De erectieprothese die specifiek is ontworpen voor de falloplastiek:

- bestaat uit één cilinder, welke breder is dan de cilinder van de prothese voor cismannen;

- heeft op de top van de cilinder een stompe glansprothese, wat minder kans geeft op erosie van het materiaal; 
- heeft aan de basis van de prothese een fixatieplaat, waardoor de prothese met vier losse hechtingen gefixeerd kan worden aan het os pubis.

Dit maakt implantatie van deze prothese in een falloplastiek makkelijker dan dat een erectieprothese die voor cismannen is ontworpen in een falloplastiek wordt geïmplanteerd.

De semirigide prothese heeft een aantal voordelen. Een belangrijk voordeel is de kortere operatietijd: de prothese is via één incisie te plaatsen en er wordt niet in de buik geopereerd. Bovendien is de prothese makkelijk op lengte te snijden. Verder is de prothese geschikt voor mensen met een slechte handfunctie. Nadeel is dat de geringe buigzaamheid van de prothese, met name bij een fallus $<10 \mathrm{~cm}$, enigszins sociaal beperkend kan zijn. Daarnaast geeft de constante rigiditeit meer kans op erosie op de top.

De hydraulische prothese bootst de fysiologische situatie van de penis beter na dan de semirigide, en is bovendien sociaal niet beperkend. Relatieve nadelen van deze prothese zijn de langere operatieduur, dat de prothese uit meerdere componenten bestaat en het relatief grote reservoir dat in het kleine bekken geplaatst dient te worden, wat in veel gevallen een extra incisie ter hoogte van de lies noodzakelijk maakt. Daarnaast is de prothese als de handfunctie beperkt is moeilijk te bedienen.

Voor beide typen prothese geldt dat bij disfunctie van de prothese (lekkage, dislocatie, malpositie of breuken) de gehele prothese (bij de hydraulische exclusief het reservoir, maar inclusief de pomp) vervangen dient te worden. Hierbij is het nodig de fixatieplaat vrij te leggen en los te maken van het os pubis en moet de nieuwe prothese opnieuw gefixeerd worden met nieuw te plaatsen hechtingen. De littekenvorming rondom de prothese en het afkapselen van de prothese zorgt voor veranderingen van de anatomie en maakt deze procedure technisch uitdagend.

$\mathrm{Na}$ implantatie van een erectieprothese voor cismannen in een falloplastiek komen frequent complicaties voor, omdat de corpora cavernosa in de falloplastiek ontbreken [7]. Als alternatief daarvoor wordt dan een vaatprothese (dacron, gore-tex) als 'sok' over de cilinders van de erectieprothese geplaatst (fig. 3), waarbij het proximale deel van de prothese door de sok gemakkelijk aan het os pubis gefixeerd kan worden [7]. Met de erectieprothese die specifiek voor de falloplastiek is ontworpen, is het gebruik van de vaatprothese niet meer nodig. De dikke tip geeft minder kans op erosie en de fixatie is geborgd door de fixatieplaat die met vier hechtingen aan het os pubis vastzit.

De sensibiliteit van de neofallus is een ander aspect dat van invloed kan zijn op complicaties na het implanteren van de erectieprothese. Sensibiliteit van de neofallus wordt bewerkstelligd door coaptatie van de sensibele zenuw van de neofallus aan een van de dorsale clitoriszenuwen ten tijde van de falloplastiek. Sensibiliteit van de neofallus is aan de ene kant van belang voor het seksueel functioneren en aan de andere kant is het idee dat deze sensibiliteit ook een beschermende rol heeft, omdat deze pijnsensatie mogelijk maakt [8]. De erectieprothese wordt op zijn vroegst een jaar na de falloplastiek geplaatst. In het verleden werd ervan uitgegaan dat na één jaar de maximale sensibiliteit van de fallus was bereikt. Recente studies hebben echter laten zien dat er tot drie jaar na de falloplastiek verbetering van de sensibiliteit kan optreden [9]. In hoeverre de sensibiliteit daadwerkelijk een beschermende rol heeft na het implanteren van de erectieprothese blijft de vraag.

In deze studie was $70 \%$ van de mannen seksueel actief en tevreden over de geslachtsgemeenschap. Het niet kunnen hebben van geslachtsgemeenschap door een te korte fallus, pijn van de prothese of het niet hebben van een partner waren de voornaamste redenen voor seksuele inactiviteit. Eerdere studies hebben aangetoond dat het seksueel functioneren van transmannen toeneemt na de gGAO en dat de gGAO goede uitkomsten laten zien ten aanzien van geslachtsgemeenschap na implantatie van de prothese [10-12]. Door de gGAO treden gevoelsveranderingen op van het genitaal die van invloed kunnen zijn op het seksueel functioneren en de tevredenheid (bijvoorbeeld moeilijker een orgasme krijgen na een falloplastiek). Goede seksuologische begeleiding is daarom van belang en dient idealiter in zowel de preoperatieve als de postoperatieve gGAO-fase te gebeuren. De toene-

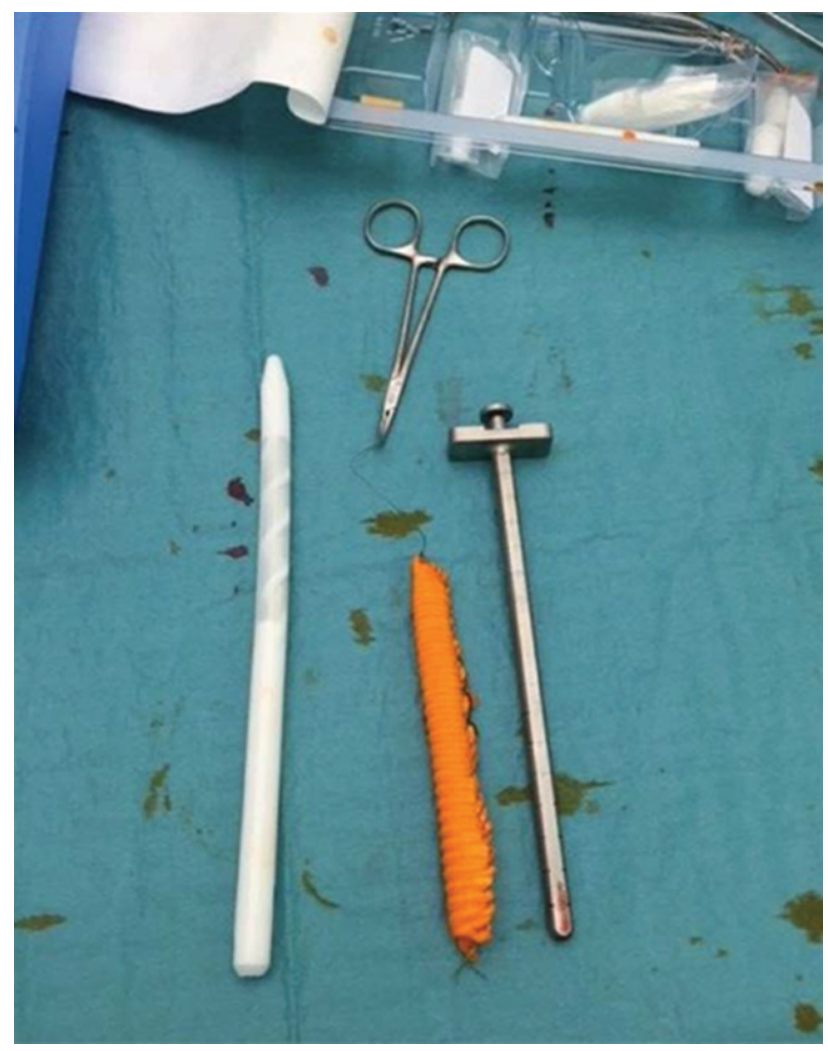

Figuur 3 Semirigide erectieprothese met de dacron prothese als sok eroverheen gehecht 
mende ervaring die wordt opgedaan met deze groep transmannen is van toegevoegde waarde voor de verdere ontwikkeling van deze seksuologische begeleiding. Op basis van shared decision making wordt bepaald of de plaatsing van de erectieprothese van meerwaarde is en wordt de indicatie gesteld voor de ingreep.

\section{Conclusie}

Implantatie van de speciaal voor de falloplastiek ontwikkelde erectieprothese laat gunstige resultaten zien. Het merendeel van de mannen is in staat tot penetratieve seks.

Open Access This article is distributed under the terms of the Creative Commons Attribution 4.0 International License (http://creativecommons.org/licenses/by/4.0/), which permits unrestricted use, distribution, and reproduction in any medium, provided you give appropriate credit to the original author(s) and the source, provide a link to the Creative Commons license, and indicate if changes were made.

\section{Literatuur}

1. Al-Tamimi M, Pigot GL, Elfering L, et al. Genital genderaffirming surgery in transgender men in the Netherlands from 1989 to 2018: the evolution of surgical care. Plast Reconstr Surg. 2020;145(1):153e-61e.

2. Elfering L, Özer M, Buncamper ME, et al. What is the ideal neophallus? Response to Frey et al. (2017): an update on genital reconstruction options for the female-tomale transgender patient: a review of the literature. Plast Reconstr Surg Glob Open. 2017;5(8):e1450.

3. Grift TC van de, Pigot GLS, Boudhan S, et al. A longitudinal study of motivations before and psychosexual outcomes after genital gender-confirming surgery in transmen. J Sex Med. 2017;14(12):1621-8.
4. Sluis WB van der, Pigot GLS, Al-Tamimi M, et al. A retrospective cohort study on surgical outcomes of penile prosthesis implantation surgery in transgender men after phalloplasty. Urology. 2019;132:195-201.

5. Neuville P, Morel-Journel N, Cabelguenne D, et al. First outcomes of the ZSI $475 \mathrm{FtM}$, a specific prosthesis designed for phalloplasty. JSex Med. 2019;16(2):316-22.

6. Pigot GLS, Sigurjonsson H, Ronkes B, et al. Surgical experience and outcomes of implantation of the ZSI 100 FtM malleable penile implant in transgender men after phalloplasty. J SexMed. 2020;17(1):152-8.

7. Blecher GA, Christopher N, Ralph DJ. Prosthetic placement after phalloplasty. UrolClin North Am. 2019;46(4):591-603.

8. Levine LA, Zachary LS, Gottlieb LJ. Prosthesis placement after total phallic reconstruction. J Urol. 1993;149(3):593-8.

9. Elfering L, Grift TC van de, Al-Tamimi M, et al. How sensitive is the neophallus? Postphalloplasty experienced and objective sensitivity in transmasculine persons. Sex Med. 2021;9(5):100413.

10. Falcone M, Garaffa G, Gillo A, et al. Outcomes of inflatable penile prosthesis insertion in 247 patients completing female to male gender reassignment surgery. BJU Int. 2018;121(1):139-44.

11. Grift TC van de, Pigot GLS, Kreukels BPC, et al. Transmen's experienced sexuality and genital gender-affirming surgery: findings from a clinical follow-up study. J Sex Marital Ther. 2019;45(3):201-5.

12. Wierckx K, Van Caenegem E, Elaut E, et al. Quality of life and sexual health after sex reassignment surgery in transsexual men. JSexMed. 2011;8(12):3379-88.

dr. Garry L.S. Pigot, uroloog

Joost W. van Leeuwen, geneeskundestudent

drs. Freek P.W. de Rooij, anios urologie

drs. Brechje L. Ronkes, uroloog

dr. Wouter B. van der Sluis, plastisch chirurg

prof. dr. Mark-Bram Bouman, plastisch chirurg 